\title{
Violencia y religación caribeña: Bicentenaire de Lyonel Tronillot
}

\section{Violence and Caribbean Religation: Bicentenaire by Lyonel Trouillot}

\section{Francisco Aiello}

Universidad Nacional de Mar del Plata, Buenos Aires, Argentina Contacto: faiello@mdp.edu.ar

https://orcid.org/0000-0002-8258-0656

\section{RESUMEN}

La literatura haitiana contemporánea ofrece una visión interior de una muy dinámica cultura, que requiere de una constante elaboración estética capaz que ofrecer líneas de sentido que permite un acercamiento a su complejidad. Este trabajo analiza la novela del escritor haitiano Lyonel Trouillot Bicentenaire (2004). Se trata de un autor que ha desarrollado toda su amplia trayectoria literaria, aún en crecimiento, dentro del país, lo cual no es un dato menor dado hay colegas de Haití que, por residir en el extranjero, han tenido el beneficio de medios de mayor circulación. El texto que nos ocupa ficcionaliza la jornada de protestas que tuvieron lugar en Puerto Príncipe el 1 de enero de 2004 -fecha en la que se conmemora el bicentenario de la declaración de la independencia haitiana- contra el presidente Jean Bertrand Aristide, quien finalmente abandonó el poder unos días después. No obstante, nuestro interés consiste en examinar vínculos intertextuales de muy variado tratamiento discursivo con textos caribeños (canciones interpretadas por Bob Marley, la novela Crónica de una muerte anunciada de Gabriel García Márquez y el drama Une tempête de Aimé Césaire como una estrategia religadora que procura inscribir la problemática de la violencia en el contexto mayor de la cultura del Caribe. Esa heterogeneidad no impide constatar dinámicas comunes que el texto de Trouillot busca poner en relación a partir de las remisiones a otros textos.

Palabras clave: Caribe francófono; Haití; Lyonel Trouillot; Violencia.

\section{ABSTRACT}

Contemporary Haitian literature offers an interior vision of a very dynamic culture, which requires a constant aesthetic elaboration capable of offering lines of meaning that allow an approach to its complexity. This work analyzes the novel by the Haitian writer Lyonel Trouillot Bicentenaire (2004). This is an author who has developed all his extensive literary career, still growing, within the country, which is not a minor fact given there are colleagues from Haiti who, because they reside abroad, have had the benefit of more media circulation. The text that concerns us fictionalizes the day of protests that took place in Port-au-Prince on January 1, 2004 the date on which the bicentennial of the declaration of Haitian independence is commemoratedagainst President Jean Bertrand Aristide, who finally leaves the power a few days later. However, our interest consists in examining intertextual links of a very varied discursive treatment with Caribbean texts (songs performed by Bob Marley, the novel Crónica de una muerte anunciada by Gabriel García Márquez and the drama Une tempête by Aimé Césaire as a re-asserting strategy that seeks to inscribe the problem of violence in the larger context of the culture of the Caribbean, whose heterogeneity does not prevent the verification of common dynamics that Trouillot's text seeks to relate from the references to other texts.

Keywords: Francophone Caribbean; Haiti; Lyonel Trouillot; Violence. 


\section{Introducción}

La estigmatización de Haití por encabezar penosas estadísticas que ratifican la precariedad de las condiciones de vida no siempre permite advertir el dinamismo de la vida cultural y artística de ese país antillano. Además, el lugar común que hace de Haití portadora de tantos padecimientos endémicos como la pobreza, la corrupción, los gobiernos autoritarios, por citar los más salientes, impide constatar que el país forma parte de un contexto mayor no ajeno a esos mismos males. La propia novela Bicentenaire de Lyonel Trouillot - escritor nacido en 1956 en Puerto Príncipe, donde actualmente reside - hace un llamado de alerta respecto de la posibilidad de considerar los conflictos de una sociedad fracturada por la violencia en el marco de la cultura caribeña; en una nota que funciona como advertencia sin firma que aparece como paratexto introductorio, una voz que podríamos atribuir al autor advierte: "Après tout, il se peut que les choses (mais lesquelles ?) se soient passées ainsi dans une île de la Caraïbe" (2004, p. 10) ${ }^{1}$.

En principio, esta aseveración parece difícil de aceptar, porque lo cierto es que la trama de esta novela recupera la jornada de protestas populares contra el presidente haitiano Jean-Bertrand Aristide - que tuvo lugar en Puerto Príncipe el 1 de enero de 2004-, aunque este mandatario no es mencionado, sin duda como estrategia de negarle entidad y de evitar que se haga foco excluyente en lo coyuntural de una figura en particular en detrimento de los planteos más sustanciales. La fecha es altamente significativa, ya que ese día se conmemoró el bicentenario de la declaración de la independencia en Haití, en 1804. Si bien la novela resulta compleja dados los cambios de punto de vista o la superposición de voces y también por las fracturas en la continuidad temporal, la línea narrativa vertebrante que se privilegia es la de Lucien, un estudiante que subsiste gracias a cursos particulares ofrecidos a la burguesía rica de la ciudad. La contraparte de este personaje se encuentra en su propio hermano, autobautizado Little Jo, quien se presenta entregado a la delincuencia armada y al consumo de drogas. A través del prisma de estos hermanos, la novela recorre la jornada registrando el incremento de la tensión social que finalmente desemboca en un enfrentamiento trágico con las fuerzas de seguridad, bajo las órdenes de Aristide. Este presidente entrega el poder unos días después - el 29 de enero de 2004 - y parte al exilio en la República Centroafricana, por lo cual transita su tercer mandato presidencial inconcluso, tras haber sido depuesto en 1991 - a pocos meses de haber asumido - y en 1994, aunque en esta ocasión logró tener apoyo de Estados Unidos para ser reinstalado en la jefatura de Estado. Estos datos que resultan ilustrativos de la inestabilidad política de Haití explican, en parte, la diseminación de la violencia en el país. Sin embargo, permiten también observar la responsabilidad de fuerzas extranjeras, como es el caso de Estados Unidos, que ha intervenido reiteradamente en la política interna tanto de Haití como del conjunto de los países caribeños, en el marco de sus intereses estratégicos en la región.

Nuestro propósito en este trabajo es realizar un recorrido a través de algunos vínculos intertextuales desplegados en Bicentenaire con textos caribeños en los que también cobra un peso central la problemática de la violencia. Buscamos probar que, a través de esos vínculos, la novela logra inscribir la situación haitiana en un contexto mayor - el Caribe - con el cual trama una religación cultural a causa de dinámicas comunes entre las que ocupa un lugar central la violencia ${ }^{2}$.

\section{Intertextos y religaciones del Garibe}

En el marco de un ciclo de charlas abiertas organizadas por la Dirección Nacional del Libro de Haití, Trouillot fue entrevistado el 8 de junio de 2020. Durante esa conversación con el periodista Wilson Paulémont difundida en directo, el autor compartió distintas ideas de orden estético, entre las cuales nos interesa rescatar la siguiente: "Personne n'écrit seul [...]. On travaille avec le travail des autres. Le texte littéraire [...] est un palymseste. C'est-àdire que c'est à la fois la négation et la réécriture de ce qui le précède" (Paulémont, 2020)․ Este tipo de afirmaciones no resultan llamativas para los estudios literarios, dentro de los cuales el concepto de intertextualidad acuñado por Julia Kristeva (1981) - que se ha vuelto dominante hasta su desgasteresuena en esta explicación de Trouillot en torno de la diversidad de textos que confluyen en cada texto en forma tanto manifiesta como tácita. De modo que el 
interés por recuperar esta idea del escritor no reside en su originalidad ni en su capacidad explicativa sobre la creación literaria. En cambio, es importante tener en cuenta que la multiplicidad de discursos orales y escritos - en este caso, una entrevista pública de difusión abierta-, con los que un escritor acompaña su obra, constituye una estrategia no solo comercial empeñada en promocionar los libros, sino también vinculada con el orden estético, en tanto las intervenciones públicas procuran regular la interpretación de los textos ofreciendo distintas claves de lectura. No nos adentramos en la sempiterna disputa entre la intención del autor y la libre semiosis según la cual cada lector escribe su propio texto, pero lo cierto es que puede reconocerse una voluntad de guiar un cierto modo de leer la producción propia, aun cuando no concedamos al escritor la autoridad exclusiva de interpretar sus producciones. Así, en este trabajo nos detendremos en algunas capas del palimpsesto a fin observar el despliegue intertextual que permite leer la novela en doble alcance: haitiano y caribeño. El análisis de los vínculos con otros textos nos permite recocer una estrategia para la construcción religadora, entendida como "vínculos efectivos" por Susana Zanetti (1994, p. 6). Si bien esta estudiosa argentina se interesa especialmente en intercambios personales, por ejemplo, a través de desplazamientos, de epistolarios o de proyectos culturales comunes, también señala la intertextualidad como modo de religación supranacional que merece ser investigada.

Mediante la intertextualidad, Bicentenaire abre un amplio repertorio de discursos entre los que se destaca la música, en particular a través de Little Joe, quien siente predilección por Bob Marley. De manera reiterada se cita la canción The rivers of Babylon; sin importar a quién sea atribuida la autoría de esta canción ${ }^{4}$, su reiterada mención conlleva la apropiación de la pieza musical en el contexto haitiano. En efecto, el intertexto bíblico sobre el que se construye la letra de la canción recupera el sometimiento a la esclavitud en Babilonia de los antiguos habitantes de Sion, ciudad que suscita melancolía por la imposibilidad del retorno. Este episodio, aludido en el Salmo 137, es aprovechado en el imaginario del retorno a la tierra de origen de gran pregnancia en el Caribe anglófono, en particular en la cultura rastafari. Tanto el sentido de protesta ante la opresión como el componente religioso de la alusión bíblica se incorporan a la cultura haitiana que comparte el trauma de la trata esclavista con el resto del Caribe y que integra el cristianismo a prácticas religiosas sincréticas que conviven con el vudú.

El contenido religioso también resuena en el título Redemption song, otra canción de Marley que acompaña a Little Jo. En este caso, la letra insiste en la memoria de la esclavitud, aunque de modo más estrechamente vinculado con la esclavitud y el traslado forzado de africanos hacia las Antillas, núcleo recuperado en primera persona como estrategia de traer al presente esa experiencia común. La redención de la que habla la canción se articula con un tono exhortativo que busca interpelar con consignas directas dirigidas a erradicar los restos de esclavitud internalizados entre los descendientes de esclavos: "Emancipate your selves from mental slavery / None but our selves can free our mind"5. Resulta evidente la resignificación de esta canción con fuerte carga apelativa en relación con la reivindicación de los grupos oprimidos en el contexto del relato de Bicentenaire, cuya acción se centra en las manifestaciones públicas que exigen renovación en la esfera política.

Además de las citaciones que tornan explícita la intertextualidad $-\mathrm{y}$, a través de ella, la religación con otras zonas del Caribe-, podemos identificar la remisión a otros textos mediante algunas expresiones: "Sans savoir qu'au bout de la marche il va mourir, ce que le lecteur sait déjà au debut du récit, prenant aussi sur le héros une inutile longueur d'avance" (Trouillot, 2004, p. 10) ${ }^{6}$. Esta anticipación del desenlace trágico del personaje principal, que encontramos al inicio de la novela, no puede sino remitir a Crónica de una muerte anunciada del colombiano Gabriel García Márquez, publicada en 1981, cuya primera frase corrobora el parentesco textual: "El día en que lo iban a matar, Santiago Nasar se levantó a las 5:30 de la mañana para esperar el buque en que llegaba el obispo" (1993, p. 9). A lo largo de Bicentenaire surge otro elemento que recuerda el texto de García Márquez; nos referimos a la precisión en el registro del transcurso personal, como se ve en esta cita: "A huit heures quinze l'étudiant a actionné la sonnerie du portail [...] Entre huit heures seize et huit 
heures dix-sept [...]. A huit heures dix-sept, exactement, le gardien a remis les choses..." (Trouillot, 2004, pp. 47-48; énfasis nuestro $)^{7}$.

Los indicios en la novela de Trouillot que reenvían al relato de García Márquez amplían la religación caribeña de lo insular hacia la tierra firme, de acuerdo con perspectivas que consideran las costas continentales bañadas por el Mar Caribe como parte integrante de la región geocultural y política del Caribe por compartir distintos rasgos, entre los que se destaca la plantación explotada mediante mano de obra esclava. El propio texto del escritor colombiano insiste en su participación en la cultura caribeña mediante distintos topónimos antillanos diseminados a lo largo de la historia y a través de una consciencia histórica que reconoce la continuidad del pasado esclavista en el presente:

Santiago Nasar señaló una lumbre intermitente en el mar, y nos dijo que era el ánima en pena de un barco negrero que se había hundido con un cargamento de esclavos del Senegal frente a la boca grande de Cartagena de Indias. (García Márquez, 1993, p. 61)

La rememoración de la trata esclavista también conlleva la recuperación del prolífico tráfico marítimo que alentó el ejercicio incesante de la piratería entre las potencias coloniales, tal como sucede en una evocación suscitada por la descripción del "decrépito edificio colonial que fuera dos días el cuartel general de Francis Drake" (García Márquez, 1993, p. 86).

Ya sea gracias a la recuperación de anónimos esclavos o a la de un célebre pirata inglés, Crónica de una muerte anunciada incorpora elementos de la historia caribeña signados por la violencia, de modo que se sugiere una línea de continuidad desde el pasado de la región hasta el presente de la narración que el cronista pretende reconstruir. Con nuevas formas de manifestación, la violencia - además de referirse al asesinato ya anticipado en la primera frase - se encuentra esparcida por todo el pueblo, lo cual se observa en el ejercicio directo sobre los cuerpos, como sucede con el trato abusivo de Santiago Nasar hacia las mujeres que trabajan en su casa. No obstante, la violencia se expresa también a través de mecanismos de exclusión que privan a los sujetos de derechos a servicios básicos, como el de sistema de justicia. Este carácter transversal de la violencia, entonces, explica la voluntad de reenviar desde Bicentenaire hacia el texto de García Márquez, lo cual se ve favorecido - como vimos - por la voluntad en la novela colombiana de integrarse en la cultura caribeña en sentido amplio.

Nuestro itinerario a través de intertextos caribeños concluye con el que, a nuestro juicio, resulta el menos evidente y el más productivo, como intentaremos probar. Proponemos un diálogo entre Bicentenaire y un texto dramático de Aimé Césaire: Une tempête, publicado en $1969^{\mathbf{8}}$.

El descontento ante el deterioro de la sociedad haitiana en diversos niveles resulta un punto de encuentro entre los hermanos Lucien y Little Jo, aunque defienden estrategias de resistencia sumamente disímiles. La confrontación de ambos jóvenes se ve reforzada por posiciones antagónicas en cuanto a los posibles modos de intervención pública, puestos en evidencia a través de la tensión entre la cultura escrita y el accionar de la violencia armada:

Il a pris un de mes libres sur la table, n'importe lequel, il l'a retourné dans ses mains [...], il a mis trente secondes à lire le nom de l'auteur, comme s'il butait sur une montagne, il a prononcé avec difficulté, en contrôlant sa respiration pour bien détacher les syllabes, Spi... no... za. Le petit n'a jamais été un grand lecteur depuis l'époque du pensionnat. Tenant sa vengeance, il a lancé le libre contre le mur, de toutes ses forces, la reliure fragile n'a pas tenu le choc, les pages détachées de la couverture se sont éparpillées dans la pièce [...] Il a sorti une arme de sa poche et il l'a posée sur la table, pour remplacer le libre, il a dit ça s'appelle un Glock, c'est mon diplôme de normalien. (Trouillot, 2004, p. 18; cursivas en el original) ${ }^{9}$

Esta escena al comienzo de Bicentenaire concentra líneas directrices que se sostienen a lo largo de la novela, en tanto el motivo que confronta los libros y las armas reaparece en distintos momentos. Así, se instala un conflicto irresuelto en un espacio de crisis aguda y prolongada, con consecuencias que penetran en el tejido social hasta el punto de enfrentar a hermanos, cuyas trayectorias vitales similares no impidieron experiencias conducentes 
a posicionamientos ideológicos irreconciliables. Mientras el mayor se aferra a ideales humanistas articulados con valores como la educación y la adquisición de una cultura libresca que otorga legitimidad a la acción civil pacifista empeñada en generar cambios sociales, el menor resignifica la exclusión y la injusticia social en términos de venganza plausible de ser ejecutada a través del uso de armas de fuego como vía de acción violenta capaz de concretar cambios que parecen irrealizables mediante los libros.

El contrapunto polémico es sostenido por dos sujetos oprimidos que instalan la disyuntiva entre acciones pacifistas e intervenciones violentas. Ello con la finalidad de producir transformaciones hacia una sociedad más justa, lo cual puede suscitar asociaciones con distintos espacios y momentos históricos del Caribe y de América Latina en general, aunque una de sus elaboraciones artísticas más resonantes es la lograda por Aimé Césaire en su reescritura del clásico shakespeariano. En efecto, en Una tempestad (2011 [1969]), el martiniqueño se apropia del clásico inglés para intervenir en distintos debates de alta relevancia en los años sesenta, tales como el impacto de movimientos revolucionarios (en particular el cubano de 1959), el acceso a la independencia de numerosos países del África y de otras regiones, así como la discusión en torno del colonialismo como problemática abarcadora. Es precisamente en relación con los debates sobre modos de despojarse del yugo del colonialismo que puede leerse el diálogo entre Ariel y Calibán, cuando el primero advierte al segundo sobre las represalias tramadas por el colonizador Próspero. El llamado a la prudencia aconsejado por Ariel encuentra determinación en la actitud combativa de Calibán. Así, los personajes confrontan posiciones sobre el modo de enfrentar al opresor:

ARIEL: No creo en la violencia.

CALIBÁN: ¿Y en qué creés entonces? ¿En tu cobardía? ¿En la renuncia? ¿En la genuflexión? ¡Eso es! Te pegan en la mejilla derecha, ponés la izquierda. Te patean la nalga, vos ponés la derecha; así sin celos. ¿Ah, sí? ¡Calibán quiere muy poco!

ARIEL: Sabés bien que no es eso lo que pienso.
Entendéme bien. Al que hay que cambiar es a Próspero. Turbar su serenidad hasta que al fin reconozca su propia injusticia y le ponga un término.

CALIBÁN: ¡Ah, bueno, dejáme que me ría! ¡La conciencia de Próspero! Próspero es un viejo rufián que no tiene conciencia. (Césaire, 2011, pp. $79-81)^{10}$

Si bien en este intercambio no reencontramos la oposición entre libros y armas, la discusión en torno del ejercicio de la violencia como modo de reivindicación de los oprimidos resulta central, al igual que ocurre en Bicentenaire. Al modo de lo que plantea la novela de Trouillot, el reconocimiento de un enemigo común no basta para aunar fuerzas en forma de resistencia conjunta. Tal como les sucede a Lucien y a Little Jo, Ariel y Calibán no logran construir un punto de encuentro capaz de conciliar la paciente esperanza de que el colonizador tome conciencia de su carácter de opresor con la decisión de confrontarlo mediante la violencia ante la certeza de que no se producirá cambio alguno en su modo de concebir el mundo colonizado y el papel que allí le toca desempeñar. Según Thomas Hale, la divergencia de posiciones obedece a la disparidad de situaciones en las que se encuentran los personajes: la postura no violenta y colaborativa de Ariel se explica porque ha obtenido algunos beneficios del sistema impuesto por Próspero; en cambio, a Calibán no le queda más opción que la lucha constante sostenida en la violencia física y verbal (1973, p. 25).

Por otro lado cabe recordar que, mediante esta polémica, Césaire refiere en forma oblicua a la situación contemporánea en Estados Unidos al momento de escritura y estreno de Une tempête. Recuperemos otro fragmento de este diálogo:

CALIBÁN: ¿Y a vos? ¿De qué te sirvieron tu obediencia, tu paciencia de Tío Tom, y todas esas lamidas? Vos lo ves bien. El hombre se vuelve cada vez más exigente y más despótico.

ARIEL: Eso no impide que haya obtenido un primer resultado, me prometió mi libertad. Con plazos, sin duda, pero es la primera vez que me la promete.

CALIBÁN: ¡Puro cuento! Te la va a prometery te 
va a traicionar mil veces. Además, el mañana no me interesa. Lo que yo quiero es [grita] "Freedom now"! (Césaire, 2011 [1969], p. 79)

La alusión al Tío Tom asume tintes de acusación porque remite al personaje de la novela de Harriet Beecher Stowe Uncle Tom's Cabin, publicada en Estados Unidos, originalmente por entregas en un periódico abolicionista entre 1851 y 1852, la cual narra las atroces peripecias sufridas en manos de sucesivos amos por el esclavo Tom, quien - no obstante - mantiene una actitud bondadosa y humilde. La expresión, incluida en inglés en el original, Freedom now, también refuerza las asociaciones con las reacciones ante la situación de opresión racial en Estados Unidos. Además, esta remisión oblicua se incrementa en un pasaje anterior - acto primero - de Une tempête, en el cual la confrontación entre Calibán y Próspero incorpora la problemática identitaria propia del sujeto sometido a la opresión colonial. Así, el habitante originario de la isla rechaza el nombre asignado por el invasor y exige:

Llamáme X. Es mejor. El hombre sin nombre. Más exactamente el hombre al cual le robaron el nombre. [...] ¡Cada vez que me llames eso me va a hacer recordar el hecho fundamental, que vos me robaste todo, incluso mi identidad! ¡Uhuru!" (Césaire, 2011 [1969], p. 69; énfasis en el original)

De esta manera, el personaje de la novela decimonónica, el grito de protesta y el empleo de la $X$ - que convoca a la figura del activista negro Malcom X (1925-1961) - constituyen indicios inequívocos del empeño, en especial para lectores y espectadores de la época, en intervenir con esta pieza dramática en debates tanto de carácter amplio - esclavitud, colonialismo - como delimitado a la situación de los afrodescendientes en Norteamérica ${ }^{11}$.

Ahora bien, si en los hermanos de Bicentenaire surgen resonancias de Ariel y Calibán, el personaje de Próspero parece no tener cabida en la analogía, puesto que la figura de autoridad presente en la historia de la novela de Trouillot - aunque velada, puesto que no está nombrada - y que carga con la responsabilidad de la represión policial contra los manifestantes no es un colonizador extranjero, sino el propio presidente haitiano Jean-Bertrand Aristide. De todas maneras, la historia haitiana del siglo XX muestra el asedio constante de los Estados Unidos como parte de su plan estratégico-militar para el control de la región caribeña (Hoffmann, 2010).

La intervención del país del Norte se concretó mediante distintas ocupaciones del territorio - la más extensa y significativa de las cuales fue la prolongada entre 1915 y 1934 - y a través de una incesante injerencia en la vida política de Haití. Repasar aquí esa historia resulta imposible, aunque basta recordar algunos episodios vinculados que ilustran el modo en que Estados Unidos acompasó la irregular trayectoria política de Aristide. De acuerdo con Carlos Sánchez Hernández (2010), el golpe militar de 1991 que lo apartó del poder por primera vez contó con el apoyo del gobierno conservador de George Bush padre, cuya administración veía con recelo la retórica izquierdista propugnada por el presidente haitiano. El pase de poder en los Estados Unidos al partido demócrata coincidió con la constatación de un recrudecimiento de las condiciones de vida en Haití y una migración ilegal creciente hacia las costas de la Florida, por lo cual el gobierno demócrata de Clinton resolvió intervenir en la política interior haitiana y decidió que lo más conveniente era el restablecimiento en Haití de Aristide. Así, el 19 de septiembre de 1994 desembarcaron en Haití 15.000 soldados estadounidenses "para restaurar el orden, restablecer una autoridad civil, y facilitar el regreso de Aristide" (Sánchez Hernández, 2010, p. 7), quien completó su mandato. Tras la presidencia de René Preval (1996-2001), Aristide volvió al poder y ocupó una vez más la presidencia. En esta nueva etapa padeció la renovada hostilidad de los Estados Unidos, cuyo gobierno de nuevo republicano a cargo de George Bush hijo volvió a contribuir con la inestabilidad política que concluyó con el exilio de Aristide hacia República Centroafricana el 29 de enero de 2004. Pese a su carácter resumido, esta cronología nos basta para advertir que, en realidad, Haití no se ha librado de su Próspero, entendido como metáfora de la injerencia extranjera para intervenir en los destinos del país en función de intereses propios. De la forma de colonización manifiesta - con presencia física del usurpador en 
la isla - de Une tempête, se pasa a estas modalidades propias de dominación velada - un Próspero que no se ve-, reforzando situaciones de asimetría entre los estados modernos ${ }^{12}$.

Así como la figura del invasor se perfila con rasgos singulares desde fines del siglo $\mathrm{XX}$ y en lo que va del XXI, también es importante volver sobre las figuras de Ariel y Calibán para señalar — pese a las afinidades examinadas - profundas diferencias con Lucien y Little Jo. En su apropiación de los personajes creados por Shakespeare, como vimos, Césaire condensa dos tendencias en cuanto a las vías para la liberación, que asimismo vincula con una caracterización racial: el intelectual Ariel es un mulato, mientras que Calibán - limitado a la explotación por trabajos manuales - es un negro. De esta manera, el poeta y dramaturgo martiniqueño pone en escena una estratificación racial que se remonta al período colonial, que distribuía roles en función del color de piel. Tal diferenciación no cabe para los personajes de Bicentenaire, puesto que se trata de hermanos que comparten el origen racial y socioeconómico, cuyo enfrentamiento resulta indicativo de las fisuras profundas ocasionadas por el deterioro del tejido social. Por un lado, nuevamente se puede observar en este cuadro de pauperización endémica y la participación de potencias extranjeras - encabezadas por Estados Unidos - con las intervenciones económicas y militares, uno de cuyos rasgos centrales es el narcotráfico ${ }^{13}$. Las consecuencias resultan evidentes en el caso de Little Jo, hasta el punto de que muchas de sus acciones incluida la de arrojar un libro del hermano contra la pared - se encuentran empañadas por los efectos de un prolongado consumo de drogas. Pero, por otro lado, la confrontación de los hermanos también actualiza el discurso autoritario impuesto por la dictadura de François Duvalier y continuada por su hijo Jean Claude. Un indicio claro de ello es que entre las figuras que reivindica Little Jo se encuentra la de Hitler, con toda la contradicción que ese gesto implica en un hombre negro. Ahora bien, su discurso aferrado a la idea de venganza, de manera menos evidente, trae a la actualidad uno de los pilares ideológicos de Duvalier padre, quien llegó a tergiversar las lecturas del etnólogo Jean Price-Mars
- reunidas en el volumen Ainsi parla l'oncle (2009 [1928]) — hasta el punto de transformar la voluntad de revalorización de la herencia cultural africana en un argumento que justificaba el ejercicio del terror amparado en el padecimiento largamente infligido al hombre negro. Duvalier racializa el conflicto social haitiano y lo reformula en la reivindicación de los negros en términos de venganza hacia la minoría mulata. Como explica Laënnec Hurbon: "Allí donde la narración de la historia en términos de lucha racial se mantiene todavía dubitativa en el siglo XIX, el discurso de Duvalier termina de fijarla estableciendo una ecuación rigurosa entre clase y raza en Haití" $(1987, \text { p. 95) })^{14}$.

\section{A modo de cierre}

La lectura contrastiva con otros textos ayuda a desentrañar sentidos más fácilmente captados por el juego de similitudes y oposiciones. Nuestro recorrido nos permite identificar una estrategia mediante la cual Bicentenaire admite, al menos, dos lecturas. La primera sería la más elemental, restringida en leer el texto a la luz del referente inmediato (los sucesos del 1 de enero de 2004). Sin duda, la novela aborda ese momento de la historia reciente de Haití - de hecho, contemporánea a la escritura-, signado por la violencia y el desamparo, pero el despliegue intertextual habilita una segunda lectura religadora que amplía la mirada y el registro de lo inmediato apelando a otros discursos que colaboran en la comprensión del presente mediante una perspectiva que se expande espacial y temporalmente.

En cuanto al espacio, es posible advertir que los padecimientos haitianos se inscriben en un contexto regional emparentado por distintos fenómenos, como la situación de dependencia o amenaza respecto de Estados Unidos o la herencia cultural que todavía está encargada de elaborar el trauma de la trata. La memoria de la esclavitud es el gran factor religador que Bicentenaire compone a través del palimpsesto en el que convergen textos del Caribe, sin perder de vista las apropiaciones desviadas realizadas en Haití de esa misma memoria como coartada para el ejercicio de la violencia justificada en el afán de venganza todavía reconocible en personajes de la novela de Lyonel Trouillot. 


\section{Notas}

1 "Después de todo, puede ser que las cosas (¿pero cuáles?) hayan ocurrido así en una isla del Caribe." Esta y todas las traducciones al español son nuestras.

2 Retomamos la noción de religación según la entiende Susana Zanetti (1994), quien la encuentra productiva por sus posibilidades de trazar líneas de conexión cultural en un subcontinente como América Latina, signado por la dispersión y la heterogeneidad.

3 "Nadie escribe solo. [...] Trabajamos con el trabajo de los otros. El texto literario [...] es un palimpsesto. Es decir, que es la vez la negación y la reescritura de lo que lo precede."

4 Si bien originalmente no es una canción del jamaiquino sino del grupo The Melodians - conjunto musical también proveniente de Jamaica-, es la versión de Marley la que Little Jo hace sonar una y otra vez a lo largo de la novela.

5 "Emancípense de la esclavitud mental / Nadie sino nosotros mismos podemos liberar nuestra mente."

6 "Sin saber que al final de la marcha va a morir, lo que el lector ya sabe desde el comienzo del relato, tomando una ventaja inútil sobre el héroe."

7 "A las ocho horas quince el estudiante presionó el timbre del portón. [...] Entre las ocho horas dieciséis y las ocho horas diecisiete [...] A las ocho horas diecisiete, exactamente, el guardia recogió las cosas..."

8 Con Une tempête (1969), el escritor y político martiniqueño Aimé Césaire (19132008) cierra su tríptico teatral iniciado en la misma década - de cambios estructurales en la política internacional por, entre otros acontecimientos, el acceso a la independencia en numerosos países del África y en algunos del Caribe-con La tragédie du roi Christophe (1963) y Une saison au Congo (1966). Gracias a esta producción dramática, el autor logra ampliar el reducido lectorado de su poesía con zonas altamente crípticas para el público general. En cambio, el teatro favorece modos de intervención en el contexto político y cultural de la época, con alusiones tanto a hechos políticos contemporáneos como a intensos debates de los que Césaire venía participando desde Discours sur le colonialisme (1950). Remitimos al excelente artículo de Florencia Bonfiglio (2013) para el análisis de los numerosos pretextos que intervienen en la composición de Une tempête.

9 "Tomó uno de mis libros de la mesa, uno cualquiera, lo giró en sus manos [...], le llevó treinta segundos leer el nombre del autor, como si corriera en una montaña, pronunció con dificultad, controlando su respiración para distinguir bien las sílabas, Spi... no... za. El pequeño nunca fue un gran lector desde la época del pensionado. Fiel a su venganza, arrojó el libro contra la pared, la frágil costura no soportó el golpe, las páginas separadas de la tapa se esparcieron por la habitación [...] Sacó un arma de su bolsillo y la dejó sobre la mesa, para reemplazar el libro, dijo esto se llama una Glock, es mi diploma de la escuela normal."

10 Citamos la traducción de Ana Ojeda que publicó la editorial de Buenos Aires El 8vo. Loco en una edición bilingüe del texto de Césaire.

11 En una entrevista concedida a François Beloux en 1969, el propio Césaire repone estas referencias sesgadas y explica que un cambio introducido respecto de la obra de Shakespeare es Ariel, que ya no es -como en la pieza inglesa- un ser aéreo y, en cambio, integra la servidumbre al servicio de Próspero: "[Ariel] es la ciencia puesta al servicio de la dominación, de la voluntad de poder. Ariel es un intelectual al servicio de Próspero; Calibán también es un esclavo, pero en un grado más absoluto [...]. Ante la dominación de Próspero, hay varios modos de reaccionar: está la actitud violenta y la no violenta. Está Martin Luther King y Malcom X (y las Panteras Negras). Para simplificar, Calibán sería la violencia y Ariel representaría la tendencia no violenta. Pero los dos, a su modo, trabajan por su liberación" (Magazine Littéraire 34, noviembre de 1969. Recuperado de https://www.potomitan.info/cesaire/politique. php, traducción nuestra).

12 Excede los propósitos de este trabajo el recorrido por los desplazamientos semánticos e ideológicos de las figuras de Próspero y Calibán en la cultura latinoamericana. No obstante, cabe apuntar al menos la significativa inversión de esta nueva apropiación que leemos en Bicentenaire respecto, por ejemplo, del planteamiento desarrollado en un texto dado a conocer un siglo antes, en 1900, como es el Ariel de José 
Enrique Rodó. Tanto en este ensayo modernista como en la novela que analizamos se reconoce a los Estados Unidos como una amenaza para el resto de América. Sin embargo, ese peligro es asociado a Calibán en el texto de Rodó, reservando para Próspero atributos de magisterio para la juventud; en cambio, a partir de los sesenta, con el trabajo de Césaire y de otros intelectuales, Próspero es leído en clave colonial y, así, porta la carga negativa del colonialismo.

13 Véase el artículo de Elsa María Fernández Andrade (2019) en el que se repasan momentos clave de la historia reciente de Haití vinculados con el narcotráfico, mediante los cuales se logra entender la confluencia de falencias internas (como la incapacidad de controlar las costas para impedir el tránsito) con distintas acciones de restricción y de deliberada desatención por parte de los Estados Unidos y otros miembros de la comunidad internacional. En otro trabajo, la autora explica: "Es, además, una política injerencista y limitante del ejercicio pleno de los derechos de terceros, porque manipula y condiciona su libre actuación para diseñar las políticas endógenas que más les convenga, porque condiciona el acceso a programas económicos y comerciales que, por supuesto, lidera Estados Unidos" (Fernández Andrade, 2017, p. 11).

14 Remitimos a nuestro trabajo (Aiello, 2013), en el que explicamos cómo la instauración de un régimen sanguinario en manos de François Duvalier lleva al propio Césaire a reconsiderar aspectos de la négritude, que ya no podían seguir pensándose en términos de panafricanismo solidario.

\section{Referencias bibliográficas}

Aiello, F. (2013). Los usos de Toussaint Louverture: relecturas de la historia haitiana en la obra de Aimé Césaire. Estudios. Revista de Investigaciones Literarias y Culturales, 41, 93-113.

Bonfiglio, F. (2013). Una Tempestad (1969) de Aimé Césaire: Una reescritura, varios pretextos. Estudios. Revista de Investigaciones Literarias y Culturales, 41, 137163.

Césaire, A. (2011 [1969]). Una tempestad (edición bilingüe). Trad. Ana Ojeda. Buenos Aires: El 8vo. Loco.

Fernández Andrade, E. M. (2017). El auge del narcotráfico en Haití y la guerra (fallida) contra las drogas. Forum, 12, 9-30.

Fernández Andrade, E. M. (2019, 9 de mayo). Narcotráfico, núcleo de la corrupción que mantiene crisis social histórica en Haití. Un periódico digital (Universidad Nacional de Colombia). https://unperiodico.unal.edu.co/pages/detail/ narcotrafico-nucleo-de-la-corrupcion-que-mantiene-crisis-social-historicaen-haiti/.

García Márquez, G. (1993 [1981]). Crónica de una muerte anunciada. Buenos Aires: Norma.

Hale, T. (1973). Sur "Une tempête" de Aimé Césaire. Études littéraires, 6 (1), 21-34.

Hoffmann, L-F. (2010). Haïti : regards. París: L’Harmattan.

Hurbon, L. (1987). ComprendreHaïti. Karthala, Henri Deschamps.

Kristeva, J. (1981). Semiótica I. Madrid: Fundamentos.

Paulémont, W. (2020). La carte de confinement de Lyonel Trouillot [Video]. Direction Nationale du Livre. https://www.facebook.com/Direction-Nationale-du-LivreDNL-193436157479337/videos/190804678881730/.

Price-Mars, J. (2009 [1928]). Ainsi parla l'oncle. Suivi de Revisiter l'Oncle. Montreal: Mémoire d'encrier.

Sánchez Hernández, C. (2010). Haití, Aristide, y la política exterior y militar de Estados Unidos (1990-2010). Nómadas. Critical Journal of Social and Juridical Sciences, 25(1). https: / /www.redalyc.org/pdf/181/18112179004.pdf.

Stowe, H. B. (1994). Uncle Tom's Cabin. Ed. Elizabeth Ammons. Nueva York: Norton.

Trouillot, L. (2004). Bicentenaire. París: Babel.

Zanetti, S. (1994). Religación. Un modo de pensar la literatura latinoamericana. El Dorado, 1(1), 5-8. 
The Monthly Review. (1806). The Monthly Review, volumen L. Londres: T. Becket.

Vásquez, C. (1999). La Ratio: sus inicios, desarrollo y proyección. Revista Portuguesa de Filosofía, 55 (3), 229-252. https://www.jstor.org/stable/40337390

Villalobos, A. (2012). La enseñanza de la historia universal antigua: participación y tipología de los Manuales de Historia en Chile republicano, 1810-1876. Revista de Historia Americana y Argentina, 52 (2), 11-40.

Willen, G. (1956). Algunas bibliotecas privadas de Lima a través de los inventarios de bienes (1800-1821). Lima: Universidad Nacional Mayor de San Marcos.

Windler, C. (1997). Élites locales, señores, reformistas. Redes clientelares y monarquía hacia finales del Antiguo Régimen. Sevilla: Universidad de Sevilla.

Zeta, R. (2000). El pensamiento ilustrado en el Mercurio Peruano (1791-1794). Piura: Universidad de Piura. 